\title{
Treacherous Ground On Some Conceptual Pitfalls in CSCW
}

Schmidt, Kjeld

Document Version

Accepted author manuscript

Published in:

Computer Supported Cooperative Work

DOI:

10.1007/s10606-016-9253-x

Publication date:

2016

License

Unspecified

Citation for published version (APA):

Schmidt, K. (2016). Treacherous Ground: On Some Conceptual Pitfalls in CSCW. Computer Supported Cooperative Work, 25(4-5), 325-353. https://doi.org/10.1007/s10606-016-9253-x

Link to publication in CBS Research Portal

\section{General rights}

Copyright and moral rights for the publications made accessible in the public portal are retained by the authors and/or other copyright owners and it is a condition of accessing publications that users recognise and abide by the legal requirements associated with these rights.

Take down policy

If you believe that this document breaches copyright please contact us (research.lib@cbs.dk) providing details, and we will remove access to the work immediately and investigate your claim. 


\title{
Treacherous Ground: On Some Conceptual Pitfalls in CSCW Kjeld Schmidt
}

\author{
Journal article (Post print version)
}

\begin{abstract}
Cite: Treacherous Ground : On Some Conceptual Pitfalls in CSCW. / Schmidt, Kjeld. In: Computer Supported Cooperative Work, Vol. 25, No. 4-5, 2016, p. 325-353.
\end{abstract}

The final publication is available at Springer via http://dx.doi.org/10.1007/s10606-016-9253-x

Uploaded to Research@CBS: September 2016 


\title{
Treacherous ground
}

\section{On some conceptual pitfalls in CSCW}

\author{
Kjeld Schmidt \\ Copenhagen Business School, Copenhagen, Denmark
}

The tangle of conceptual issues that conventionally, in CSCW research, is referred to by the term 'awareness' (mostly with a qualifying adjective such as 'reciprocal' or 'mutual') poses a major challenge to CSCW. On one hand there is widespread agreement that the phenomena referred to by that term are somehow critical for collaboration technologies to become integral complements of cooperative work practices, but on the other hand confusion reigns as to how those phenomena are to be conceived of or even described.

The disconcerting fact is that the term 'awareness' is being used in reference to rather different phenomena: to 'collaboration aware' software programs (e.g., Lauwers and Lantz 1990; Dewan and Choudhary 1991), or to actors' knowing and taking into account the wider organizational context (e.g., Dourish and Bellotti 1992; Dourish and Bly 1992), or to 'shared situation awareness' in the form of intersecting datasets (e.g., Endsley 1995; Endsley et al. 1999; Endsley and Jones 2001), or to more or less subtle means of directing attention (e.g., Nardi et al. 2000), or to the sentient stance of skilled actors as they effortlessly and reciprocally align their individual contributions to the cooperative effort (e.g., Harper et al. 1989; Heath and Luff 1992; Harper and Hughes 1993) ${ }^{1}$. Worse still, perhaps, there is a manifest tendency for different research traditions within $\mathrm{CSCW}$ to simply ignore the existence of different conceptualizations of 'mutual awareness', or of the different uses of the term, and to proceed, for instance, in exploring the affordances and challenges of, say, 'shared interfaces', 'augmented reality', etc. as if the conceptual problem of 'mutual awareness' has already been solved and hence a state of intellectual harmony achieved.

In their article in this issue of the CSCW Journal, Josh Tenenberg, WolffMichael Roth, and David Socha (2016) put an end to this intellectually untenable state of affairs, by confronting established positions in CSCW with an articulate critique. With that, we can no longer proceed as if we do not have a problem. For that alone Tenenberg et al. are to be commended. Moreover, irrespective of whether or not one agrees with their conception of the problem or accepts the solution they outline, by proposing an alternative conceptualization grounded in respectable intellectual traditions, and by supporting their argument by a very rich

\footnotetext{
1 Actually, the earliest of these studies did not use the term 'awareness' but described the observations in different ways (e.g., 'monitoring', 'noticing'). However, the term 'awareness' was later imported into that line of CSCW research as a label for actors' 'monitoring', 'noticing', etc. (cf. e.g., Heath et al. 1993; Heath and Luff 2000; Sellen and Harper 2001; Heath et al. 2002).
} 
study of an instance of intense cooperative work, they force us, the CSCW research field, to critically rethink that whole bag of issues.

Now, as it happens, I have myself, for more than two decades, tried to get to terms with how we can understand what we have termed 'mutual awareness' and have written extensively about the problem (Schmidt 1994a, b, 1998b; Schmidt and Simone 2000; Schmidt 2002a, b, 2011). I also happen to be the author of some of the texts Tenenberg and his colleagues target in their critique (2002a, 2011). However, while I find their rendition of my position as expressed in these texts inaccurate and in places somewhat distorted, I will abstain from corrections and counter-interpretations: it is history anyway, and, more importantly, I accept that what I have previously written on these issues leaves much to be desired. So instead of justification I will try to move the discussion on the issue of 'mutual awareness' in CSCW forward by offering a critique of the solution suggested by Tenenberg et al. and, pursuant to that, by addressing the obvious shortcomings of my previously stated position on 'mutual awareness'. I hope this will also contribute to clarifying this longstanding issue.

\section{The challenge}

Tenenberg, Roth, and Socha raise serious objections against the notion of 'mutual awareness' as used in CSCW. If I understand them correctly, their argument consists in a two-pronged advance.

First of all, they find a conception of 'mutual awareness' common to the work of Toni Robertson, Christian Heath, Paul Luff and others, as well as myself, and characterize it as 'a first-person perspective that black-boxes the intentionality of others, focusing only on the actions, communication, and resources that are "publicly available"" (Tenenberg et al. 2016, § 1). This conception, they find, 'stops at the boundaries of skin and skull: one heeds what one can perceive of others without regard to their beliefs or goals' $(\S 2)$. That is, it is a conception of cooperative work that portrays workers as hard-nosed behaviorists. Or as they summarize their critique, 'the minds of the individual actors are black-boxed':

\footnotetext{
'Heeding strategies, both the displayed and monitored, are [exploit?] the publicly available resources within a particular setting. Explicitly excluded are the beliefs and goals of self and other. Such mentalistic entities are simply unavailable to actors, and do not figure in the ways in which people are heedfully aware of one another in their ongoing, situated activities. The awareness of social actors is thus no more - and no less - than the aggregation of the awareness of the individuals who comprise the group in interaction, the aggregation of myriad atomic acts.' (Tenenberg et al. 2016, § 2).
}

Against this conception Tenenberg et al. argue that collaborating workers, in performing their activities, not only 'heed' what others are doing, moment by moment; they are, in doing so, exhibiting 'shared intentionality'. That is, the subtle and effortless coordination to which the term 'mutual awareness' alludes is constituted by workers' possessing or developing 'shared intentionality'. In 
introducing this notion of 'shared intentionality' they draw on a respected thread in modern philosophy of action that is concerned with the problem of 'collective intentions', in particular the work of John Searle (1990, 1995), Margaret Gilbert (1992), Michael Bratman (1992, 1993), and especially Michael Tomasello (e.g., 2005; 2009, 2014). ${ }^{2}$

In the second prong of their argument, Tenenberg et al. stress that 'shared intentionality' 'depends' on or is 'based' upon or is 'underwritten' by what Herbert Clark (e.g., 1991) has termed 'grounding', that is, the process of achieving 'common ground', a process Tenenberg et al. prefer to call 'socially recursive inference'. Instead of simply hypothesizing 'shared intentionality', they want to investigate the process through which such 'shared intentionality' is established, maintained, and repaired (e.g., §§ 1,3, 5.3).

'We-awareness goes beyond aggregated I-awareness. Our claim is that the heeding strategy that each person can at the same time see the computer monitor and what the other person is seeing is not enough to account for Henry and David's accomplishment of cooperative work. What is further required is that David and Henry each can assume that the other is oriented in the same way, and they know that they can assume this, ad infinitum. That is, they engage in socially recursive inference and presuppose it of their partner in shaping and interpreting their actions and those that they perceive in their shared environment.' (Tenenberg et al. 2016, § $5.3)$.

In sum, then, what Tenenberg et al. take exception to is an account of cooperative work in which the very phenomenon of concerted action comes across as the aggregated result on myriad atomic actions, as when hydrogen bonds in water molecules in a glass lead to surface tension strong enough for insects to skate upon it. They find this to be an utterly impoverished and unsatisfactory conception of cooperation which does not account for the 'accomplishment of cooperative work'. Against this, they offer an account that posits, first, that cooperative work presumes 'shared intentionality', and, second, that this 'shared intentionality', as 'common ground', is 'recursively' established and maintained:

'Shared intentionality [...] provides a basis for reconceptualizing awareness in CSCW research, building on and augmenting existing notions of individual intentionality. And it is just such a reconceptualization of awareness, from "mutual awareness of something" carried out seamlessly and effortlessly (Schmidt 2011), to a "shared awareness of something that each recursively knows of the other" that we provide in this paper.' (Tenenberg et al. 2016, $\$ 2$ ).

This is a very ambitious undertaking indeed!

This commentary will focus on a critical discussion of the notion of 'shared intentionality' (and its support notions, 'sharing' and 'common ground') as developed in the literature Tenenberg et al. advocate as ' $a$ basis for reconceptualizing awareness in CSCW research', primarily in the work of Tomasello but also Clark. Towards the end of the commentary, I will revisit the notion of 'awareness' and suggest that it frames the research problem in a way that leads nowhere.

\footnotetext{
2 A useful and critical overview of this literature is given by David Schweikard and Hans Bernhard Schmid
} (Schweikard and Schmid 2013), 


\section{Common ground, after a fashion}

The gist of the critique Tenenberg et al. raise is that 'the heeding strategy that each person can at the same time see the computer monitor and what the other person is seeing is not enough to account for [workers'] accomplishment of cooperative work' ( $\$ 5.3)$. The short answer is 'Yes, sure!'. But then the notion of workers' heeding the activities of others was never meant to do that job either. Neither was, for that matter, the notion of 'mutual awareness'. As far as I am concerned, the discussion of how workers, in doing their individual bits, generally act in awareness or take heed of what others are doing and not doing is entirely predicated on the concept of 'cooperative work' as developed over the years and would not make much sense outside of that context (Schmidt and Bannon 1992; Schmidt 1994b, 2002b). As I expressed it in my introduction to the special issue of the CSCW Journal on 'Awareness in CSCW' (2002a, p. 285), the tangle of conceptual issues we bundle by using the term 'mutual awareness' arose as researchers realized that 'cooperating actors somehow, while doing their individual bits, take heed of the context of their joint effort'. In other words, the whole web of issues was seen as internally related to the notion of 'the context of their joint effort', that is, to the concept of cooperative work.

Although the term 'awareness' is used rather promiscuously in CSCW, it is not meant to do the job of explaining the accomplishment of cooperative work. In fact, it does not explain anything but, rather, characterizes certain patterns of conduct in cooperative work settings. As it has been generally used, it presumes that work is already, somehow, constituted as cooperative work, work in relations of interdependence, typically as a consequence of division of labor. Thus, the term 'mutual awareness' is often - typically, perhaps, but certainly not always - used in reference to some rather elusive patterns of conduct. In contrast to the refined and specialized coordinative practices with concomitant specialized coordinative artifacts, the term 'mutual awareness' is typically used in reference to manifestations of actors' exercising subtle coordinative competencies acquired and refined through training and months or years of work experience. What makes the manifestation of these competencies somewhat elusive is that they are enacted as aspects of actor's doing their work. That is, the term does not refer to a specifiable set of work activities but rather to the manner in which work activities are conducted. - This, I submit, is also a rather serious problem with this conception and for this line of $\mathrm{CSCW}$ research. I will revert to this issue towards the end of this commentary.

That said, how would we, under the auspices of the concept of cooperative work, account for workers' 'accomplishment of cooperative work'?

The immediate answer is that we would do that, first, by accounting for the way work is organized: in modern industrial societies, the whole contractual edifice of employment contracts, job profiles, budgets, performance measurement schemes, and related to this by describing the repertoire of reward and punishment measures available to management such as, on one hand fringe benefits, salary 
increases, and promotions and, on the other, fines, demotions, discharges, tribunals, and lawsuits, but also the repertoire of countermeasures available to workers. We would furthermore account for the accomplishment of work by describing the ways in which work is divided into tasks; how tasks are assembled into jobs; how tasks and responsibilities are assigned to individuals or roles and collectives; how individuals routinely assume or accept roles and tasks; how tasks and activities are interlinked and scheduled, and so on. Without this kind of organizational framework, systematic division of labor would be impossible.

But crucial as this entire organizational framework may be, it is just that: an organizational framework. Cooperative work is first and foremost accomplished by competent workers. So, to account for the 'accomplishment of cooperative work' we would have to identify and describe the web of work practices and the general principles to which practitioners are committed and that constitute the rationale of their activities (categorizations, key concerns, priorities, criteria of success, procedures, etc.). We would furthermore have to understand the ways in which these practices are institutionally formed and situated, by identifying and describing how practitioners are educated and trained for the kind of work they do, and the professional standards of conduct, professional honor, institutional ethos, and, indeed, esprit de corps, to which they may be devoted, committed to do their best. And we would finally need to identify and describe the techniques workers rely on in their practices (tools, instruments, and other artifacts, as well as bodily skills); the specialized coordinative practices and the concomitant coordinative artifacts; and of course the behavioral modalities by means of which workers take heed of unfolding developments in the settings, the accidental or deliberately provided resources in the settings they exploit in doing so, the ways in which these practices are upheld and passed on through instruction and emulation, and so on. That is, we would account for the orderly accomplishment of cooperative work by being specific.

But for CSCW purposes we do not always, or even typically, go all in and give a comprehensive description of the organizational framework and institutional underpinning of the cooperative work settings we study, and we do not do that for the simple reason that we do not necessarily need to in order to understand how workers integrate and coordinate their distributed but interdependent activities. However, our bracketing the organizational framework and institutional underpinning of work practices may also give rise to the impression that we ignore the normative constitution of the work practices we observe, and even to the objection that we are giving 'behavioristic' accounts of cooperative work. One might object that such an impression or objection is not quite fair, which is true; but then again, a description of a cooperative work practice that effectively leaves out or marginalizes the normative constitution of work practices (as mediated by the whole complex of organizational framework and institutional framework) is a mere torso. It runs the risk of giving an account of cooperative work that reduces the accomplishment of order in cooperative work to the means (the embodied as well as artifactual techniques) by virtue of which order is maintained, which, in 
turn, results in a caricature of work practices. As Wittgenstein put it in a lecture on the philosophy of psychology:

'If I classified the activities of human beings by their bodily movements it would be most misleading. It isn't the point that an author, a bank clerk, a grocer makes different bodily movements; in describing their behaviour the subsequent fates of the MS [manuscript], cash, groceries are relevant. To leave them out is like leaving out a dimension in describing a body and comparing only cross-sections.' (Wittgenstein 1946-47, p. 42).

So far, I think we have some common ground.

\section{Shifting ground, or 'shared intentionality'}

The stated aim of the article by Tenenberg et al. is to 'provide a philosophically grounded conception of awareness based on shared intentionality'. Now, it is said that 'One doesn't look a gift horse in the mouth', but then it was also said among the old Germanic tribesmen that one should 'Receive gift with spear, point against point'. So, before we accept the conception we are presented with, let us carefully inspect the teeth of this gift horse, and its legs too. Let us inspect the 'philosophically grounded conception of awareness based on shared intentionality' that is being offered for the purpose of 'reconceptualizing awareness in CSCW research'.

\section{1 'Collective intentions', according to Searle}

In the recent philosophy of action tradition, the notion of 'shared intentionality', or rather 'collective intentions', was first expressed by John Searle (1990; 1995, pp. 23-26). He observes that we are inclined, by 'intuition', to talk about 'collective intentions' in the following sense:

'collective intentional behavior is a primitive phenomenon which cannot be analyzed as just the summation of individual intentional behavior; and collective intentions expressed in the form "we intend to do such-and-such", and, "we are doing such-and-such" are also primitive phenomena and cannot be analyzed in terms of individual intentions expressed in the form "I intend to do such-and-such" or "I am doing such-and-such". (Searle 1990).

Can we defend such a notion without subscribing to mysterious notions such as 'group mind'? By way of replying, Searle sketches a conceptual analysis of this area of ordinary language, arguing that 'the simplest way to see that collective behavior is not the same as the summation of individual behavior is to see that the same type of bodily movements could on one occasion be a set of individual acts, on another occasion they could constitute a collective action'. There is a categorial difference between saying 'The orchestra is playing Beethoven's 5th symphony' and saying 'The musicians are playing their respective instruments and what comes of it sounds unmistakably like Beethoven's 5th'.

The argument is related to the one Gilbert Ryle developed in his discussion about 'thick description': there is a categorial difference between describing an 
action as 'There was a momentary contraction of his left eyelid' and as 'He was winking', just as there is a categorial difference between saying 'The man is writing his signature' and 'The man is signing a peace treaty' (Ryle 1966-67, 1968). The difference is one of domain of discourse and, related to that, criterion of adequate description. In describing an action as intentional, as opposed to accidental or taken unknowingly, we are in a discourse where members' criteria of adequate description call the day (Anscombe 1957). Accordingly, we can say of Oedipus that he was in love with Jocasta, but not that he was in love with his mother; he just, accidentally and tragically, did not know that said Jocasta was in fact his mother.

Searle (1990) concludes that we can indeed talk intelligibly about 'collective intentions' or 'we intentions': 'We simply have to recognize that there are intentions whose form is: We intend that we perform act A; and such an intention can exist in the mind of each individual agent who is acting as part of the collective.' Or as he put it a few years later: 'I intend only as part of our intending' (1995, p. 26). That is, Searle argues, the notion of 'collective intention' does not presume that the actor is correct in expecting reciprocity, only that he takes reciprocity for granted in his acting: 'Of course I take it in such cases that my collective intentionality, is in fact shared; I take it in such cases that I am not simply acting alone' (Searle 1990).

So far, I have no qualms with the notion of 'collective intention'.

\section{2 'Shared intentionality', according to Tomasello}

As in Searle, the problem that is addressed in much of the literature on 'collective intentionality' (e.g., Tuomela and Miller 1988; Bratman 1992), is whether we can talk intelligibly about such intentions ('we-intentions') in a non-reductive sense and, if yes, how. This movement can be seen as a continuation of the critique of the skepticist notion of the mind as an insular entity struggling to make sense of the world and the other minds that supposedly populate it.

The ambitious project pursued by Tomasello and his colleagues at the Max Planck Institute for Evolutionary Anthropology in Leipzig draws on the work of Searle, Bratman and other recent contributions to the philosophy of action but is also distinctly different in that the researchers move the argument from the discourse of conceptual analysis (back) to that of cognitivism. Their research question is that of the phylogenetic and ontogenetic origins of human 'cooperation', that is, human sociality: the 'social' or 'cooperative motivations' and 'recursive mind-reading skills' that presumably underpin our disposition to engage in altruistic and mutually beneficial actions (from sharing meat with others, to sharing information, to offering help, to engaging in conversation), our symbolic interactions, our sign systems, our collaborative activities, even our institutions, and so forth (e.g., Tomasello et al. 2005; Tomasello 2008, 2009, 
2014). ${ }^{3}$ The focus on 'cooperative motivations' arises because Tomasello, in order to understand the evolution of 'human cognition' ('cultural cognition'), 'human communication', and 'cooperation', has to engage with biological theory of evolution and the fundamental role it ascribes to competition among conspecifics in the selection process. But he also choses to build on game theory and its dismal calculus of individual benefits of 'non-cooperation' versus 'cooperation'. And, not least, he draws heavily on cognitive psychology and its assumption of the insular mind building 'cognitive representations' to cope with the world.

Tomasello et al. first introduced the notion of 'shared intentionality' in 2003 (Tomasello and Rakoczy 2003) and developed it further in a widely cited programmatic article in Behavioral and Brain Sciences two years later (Tomasello et al. 2005).

This is the overriding hypothesis pursued in the work of Tomasello over the last decade, as originally formulated:

'We propose that human beings, and only human beings, are biologically adapted for participating in collaborative activities involving shared goals and socially coordinated action plans (joint intentions). Interactions of this type require not only an understanding of the goals, intentions, and perceptions of other persons, but also, in addition, a motivation to share these things in interaction with others - and perhaps special forms of dialogic cognitive representation for doing so.' (Tomasello et al. 2005, p. 676).

To understand the notions of 'shared goal', 'joint intentionality', and 'shared intentionality' as used by Tomasello et al., it is first helpful to keep in mind what the authors mean by what is supposedly 'shared', 'goals' and 'intentions'. Following Bratman (1989), they 'propose that an intention is a plan of action the organism chooses and commits itself to in pursuit of a goal. An intention thus includes both a means (action plan) as well as a goal' (Tomasello et al. 2005, p. 676). Furthermore, in making this distinction (intention $=$ goal + plan) they "employ a "control systems" approach (from cybernetic theory) to characterize the structure of intentional action' on the one hand, and on the other 'a "shared intentionality" approach (from the philosophy of action) to characterize the types of cognitive skills and social engagements that make possible uniquely human activities [...]' (p. 676). As for 'the structure of intentional action', they 'propose a simple model based on control-systems principles - in which goal, action, and

\footnotetext{
3 It should be remarked, in passing, that while Tomasello's research question is a question as ambitious as that of the origins of life, Tomasello et al. base their theorizing on experimental studies with apes in captivity and with human infants. They only include, for contrast, a few and rather brief observations from studies of primate behavior in the wild (from the extant literature), but do not consider the large body of ethological studies of animal sociality, nor do they consider the relevant paleoanthropological, ethnographic, archeological, and historical literatures. However, in spite of the narrow basis of the research, Tomasello speculates that 'collaborative activities' such as cooperating hunting or building a shelter play a key role in the evolution of the cognitive capacities of human kind (e.g., 2008, 2009) but seems unaware of the massive evidence indicating that cooperative work (in the sense of productive and reproductive activities performed in relations of interdependence, as opposed to socially organized activities in general), appears rather late in hominid evolution and only occurs sporadically in hunter-gatherer societies and even in pre-industrial agricultural societies (e.g., Lee and DeVore 1968; Rösener 1985; Johnson and Earle 1987; Crone 1989).
} 
perceptual monitoring are all seen as components in the larger adaptive system that serves to regulate the organism's behavioral interactions with the environment' (p. 676). To illustrate this notion of 'goal' they refer to the regulatory function of the ordinary thermostat. Thus,

\begin{abstract}
'When it is said that a person wants a box open, for example, we may distinguish the external goal - a certain state of the environment such as an open box - and the internal goal - an internal entity that guides the person's behavior (e.g., a mental representation of a desired state such as an open box).' (Tomasello et al. 2005, p. 676).
\end{abstract}

That is, Tomasello and his colleagues are committed to retaining the mechanistic thesis underlying cognitivism, namely, that rational conduct is the result of the regulatory effect of some 'internal entity'. while at the same time trying to account for the 'shared', 'cooperative', or 'collaborative' activities of multiple persons. The problem they face in this is how to understand the putatively 'shared goal' (which, presumably, would have to be a both 'internal' and 'shared' 'entity') and similarly 'shared intentionality' ('shared goal' with associated 'shared' action plan). In short, they have to retain the radical mentalism of cognitivism while accounting for 'cooperation'. That is a tall order by any standard. Let us see how they manage:

'Shared intentionality, sometimes called "we" intentionality, refers to collaborative interactions in which participants have a shared goal (shared commitment) and coordinated action roles for pursuing that shared goal [...]. The activity itself may be complex (e.g., building a building, playing a symphony) or simple (e.g., taking a walk together, engaging in conversation), so long as the interactants are engaged with one another in a particular way. Specifically, the goals and intentions of each interactant must include as content something of the goals and intentions of the other.' (Tomasello et al. 2005, p. 680). ${ }^{4}$

Let then us look at what Michael Tomasello and his colleagues say about 'shared intentionality' in what is presented as an example of cooperative or collaborative activity. When two persons engage in the collaborative activity of, for instance, opening a closed box, the following is supposed to be required (I quote at length, to give readers unfamiliar with this literature a chance of judging the case):

'First and most important, the cognitive representation of the goal contains both self and other; that is, it contains not only the self's goal that the box be open, but also the self's goal that this be accomplished with the partner. One might simply say, then, that his goal concerns their mutual actions. But since he does not have expectations about the partner's particular behaviors, but rather about her intentional actions (as defined by goals such as opening the box), we may better say that the actor wants his interactant to have, along with him, the goal of opening the box - which she should pursue using whatever means are necessary. And of course the partner, assuming she also desires collaboration, also wants her partner to share her goal thus creating a "shared commitment" [...]. And so, overall, [...] there is a special kind of shared motivation in truly collaborative activities in the form of a shared goal - each interactant has goals with respect to the other's goals [...].

\footnotetext{
${ }^{4}$ Note that the authors are not just talking about 'cooperative work' in the strict sense of division of labor in production and similar but about manifestations of human sociality in any kind of action where 'interactants are engaged with one another in a particular way'.
} 
The second important aspect [...] is that the cognitive representation of the intention also contains both self and other - it is thus a joint intention. This is necessary because both collaborators must choose their own action plan in the activity in light of (and coordinated with) the other's action plan: my role is to hold the box steady while you cut it open. This requires that each participant cognitively represent both roles of the collaboration in a single representational format - holistically, from a "bird's-eye view," as it were - thus enabling role reversal and mutual helping. Overall, then, collaborative activities require both an alignment of self with other in order to form the shared goal, and also a differentiation of self from other in order to understand and coordinate the differing but complementary roles in the joint intention.' (Tomasello et al. 2005, pp. 680 f.).

The first thing to observe here is the liberal way in which Tomasello et al. impute all kinds of intermediate cognitive states and processes. The authors talk about an 'internal goal' as 'an internal entity' such as 'a mental representation of a desired state such as an open box' that 'guides the person's behavior'. The term 'shared intentionality' is similarly used in reference to interactions that are 'collaborative' because participants 'have' a 'shared goal' or 'shared commitment' as well as a 'cognitive representation of the goal' which in turn 'contains both self and other'. And so on. In fact, their liberalism sometimes descends into anarchism. Notice that the authors take great care to instruct us that they employ a controltheoretical model of intentional behavior in which the organism's behavior is regulated by an 'internal entity', analogously to the functioning of a thermostat, but then equate 'shared goal' with the notion of a 'shared commitment'. But a 'goal' in the control-theoretical sense, where one can talk about a thermostat's striving to achieve a goal, cannot be made equivalent with a concept like 'commitment'. That is simply a category mistake of the first order. There is no place for 'commitment' in control theory! Or does this mean that a 'goal' ceases to be a 'goal' when 'shared'? Though foundational to the argument, this is incoherent.

It is anyway debatable if the notion of a 'goal' as used here does any real work. In which sense of 'goal' does it make sense to say that workers have a goal, shared or not? The dictionary would suggest that we by 'goal' could mean 'desired result of an effort'. That would make sense if the work under consideration has the character of a project (building a house, say) but is the desired result necessarily known in advance in the case of a design project or a research project? And what is the goal of a teacher? We could easily list a number of success criteria for the teaching job but they would most likely contain competing or mutually contradictory criteria. But then we are not really talking about goals but of the work of handling trade offs (under duress). And last, does the goal of a nurse change whenever she attends to the next patient? Is it the same goal when she takes the the patient's temperature and then places a cold cloth on his feverish forehead? That is, what is the criterion for ascribing a goal? What is the criterion of granularity for determining goals? In short, the discourse about 'goals' (and by analogy, 'intentions') may appear commonsensical but it is deficient in realism: the sign of unfettered theorizing. 
The second thing to notice is that there is something fishy going on. Each member of the box-opening team has as his or her goal to open the box and to do it together, which is an intelligible expression. But instead of elaborating how this cooperative effort comes about and is performed by the two persons (A may have said: 'Opening this box may be tricky, will you help?', upon which B came into the room and faced the box, ready to help), the authors switch from persons to 'cognitive representations', by introducing a notion that 'the cognitive representation of the goal contains both self and other; that is, it contains not only the self's goal [...], but also the self's goal that this be accomplished with the partner', and vice versa, which does not add anything other than cognitivist jargon to the intelligible statement that the two persons aim to open the box together. But then, in the second paragraph of the quoted passage (pp. $680 \mathrm{f}$.) they switch gear: It is important, they argue, that 'the cognitive representation of the intention also contains both self and other' which in turn 'requires that each participant cognitively represent both roles of the collaboration in a single representational format' 'in order to understand and coordinate the differing but complementary roles in the joint intention'. This begs a bag of questions.

First, how does A know that he and B have a shared goal? Because he has a cognitive representation of B's goal? How does he know that it is the correct one? And how does this 'single representational format' emerge? Where does it reside? Furthermore, when Tomasello et al. state the obvious, namely, 'One might simply say, then, that his goal concerns their mutual actions', and then add: 'But since he does not have expectations about the partner's particular behaviors, but rather about her intentional actions', they are causing confusion. Why are they not, unlike Searle and most of humanity, satisfied with that rather straightforward expression, which simply says that they agree to work together to get the box opened and says nothing about the actually unfolding process? Because, I submit, they are in the business of transplanting a predicate such as that of 'having a shared goal' from persons to 'cognitive representations'.

All in all, what we are presented with here is a new and updated variant of what Gilbert Ryle aptly dubbed 'the intellectualist legend' (Ryle 1949). The legend invariably presumes that intelligent, rational, etc. action by necessity requires some anterior cognitive operation of planning, calculating, etc. 'To put it quite generally, the absurd assumption made by the intellectualist legend is this, that a performance of any sort inherits all its title to intelligence from some anterior internal operation of planning what to do' (p. 31). There is of course no denying that intelligent action - giving an illuminating lecture, for example sometimes involves even extended preparation and reflection, but that does not necessarily apply to each and every performances we judge as intelligent, rational, etc. A tennis play may play intelligently, etc. without having a readymade plan before entering the court or before serving. The problem with the presumption that prior planning, calculation etc. is necessary is that the presumed prior operation may itself be faulty, and that this prior operation in turn, to be intelligent, rational, etc., would require yet another, further anterior, operation to 
be intelligent, rational, etc. And so on, ad infinitum. ${ }^{5}$ That is, the fallacy of intellectualism manifests itself in infinite regress. Arthur Kenny, less respectfully, dubbed this kind of fatally flawed reasoning 'the homunculus fallacy', namely, the fallacy of taking 'predicates', such as to 'have a goal', to 'represent' something etc., 'whose normal application is to complete human beings or complete animals' and applying them to 'insufficiently human-like objects' such as the mind, the brain, etc. (Kenny 1971).

Intellectualist accounts do not explain anything; they merely replace one description of a phenomenon with another, while pretending to be explaining it. It is this juggling with equivalent descriptions that shows itself in infinite regress. In other words, the unofficial hallmark of intellectualist accounts is that they always, in some way or another, introduce a homunculus.

However, in Tomasello's case this juggling is couched in his use of the picture of 'sharing'. We therefore, as our next step, have to unpack this picture.

\subsection{The 'sharing' pitfall}

In our kind of research, the phenomena under study - collaboration, cooperative work practices, use situations, user preferences - are constituted in and through actually unfolding ordinary social life and are thus invariably defined in terms of ordinary language: in terms of ordinary-language concepts such as 'goal', 'task', 'knowledge', 'skill', 'division of labor', 'coordination', 'organization', 'practice', and so on and so forth. The same applies to notions such as 'shared goal', 'shared understanding', 'shared knowledge', 'shared intention' or 'shared intentionality', etc. Given the burden to be carried by the notion of 'sharing' in Tenenberg et al., as well as in the philosophical work they mobilize, it is advisable to consider the ways in which we ordinarily use the term 'shared'.

The verb 'to share' (and the adjective 'shared') is used in a bewildering variety of ways. What we have, in fact, is a family of metaphors that, well, share the same word and have been derived from the old Germanic word for an act of partitioning and for the result of partitioning: to share, as in 'to shear', to cut through (cf. 'plowshare': the implement that cuts the soil).

Thus, to 'share' may simply mean to divide or partition a thing into discrete parts for separate consumption or appropriation. One 'shares' a six-pack of beer or a chocolate cake with friends by dividing it into portions and handing these out. One can also, in a related sense, buy 'shares' in a corporation and then be entitled to receive a 'share' of the company's profit: a 'dividend' (from the Latin verb dividere, force apart). However, the term may also be used to express that

\footnotetext{
5 Ludwig Wittgenstein makes a parallel move when he applies an ad absurdum argument in his demolition of the similarly intellectualist insistence that normatively regulated conduct such as speech, calculation, etc. ('rule-following') necessarily involves 'interpretation' of the 'rules': 'any interpretation still hangs in the air along with what it interprets, and cannot give it any support. Interpretations by themselves do not determine meaning' (Wittgenstein 1945-49, § 197). For another move of this sort, see his so-called 'private language argument' (\$§ 243 ff.).
} 
multiple persons have de facto access to a resource. We all 'share' the planet and its atmosphere (although some obviously are 'more equal than others'). But the word 'share' is also sometimes used to denote legitimate access to one's resources: 'What's mine is yours'. In a similar vein, the phrase 'sharing a fridge' is used to express that multiple persons can legitimately access and consume the provisions held in the fridge: 'shared' here is used to denote rights in terms of property or possession. By contrast, the phrase 'a shared bed' does not (in a civilized world) express that occupants are at liberty to divert themselves with the other occupants. What is shared here is not the content but the horizontal sleeping facility as furbished with mattress and duvets, whereas in the case of the fridge it is the content that is 'shared' and not merely the fridge as a cooling facility. Sharing a six-pack or a cake is quite different from the 'sharing' of a fridge or a bed or a planet: the shared cake and six-pack and the shareholder dividend are no longer there for sharing after having been 'shared', whereas the shared planet and its atmosphere as well as the fridge and the bed are still there afterwards (although the planet may begin to look worn and the contents of fridge and bed may have vanished the next day). The word 'share' may similarly be used to refer to tools and materials that are available to workers at a workplace in the sense that they can freely use these resources while at work, but it would be considered illegal if they were to remove the resources from the premises.

Notice the metaphorical drift. In expressions such as 'to share a cake', the sense of partitioning by cutting is retained: we 'shear' to 'share' it. But when using the term 'share' in the case of 'a shared fridge' or 'a shared bed', nothing is 'shorn', and we have abandoned the original metaphor of cutting through; it is now the justifiability possession that is expressed.

There is a certain logic to this metaphorical drift. To 'share', in the sense of partitioning something and handing out the resulting portions, amounts to more than cutting and moving but also to granting legitimate access. 'Sharing' in this sense consists in issuing an entitlement or a pledge; that was, after all, the point of partitioning. But entitlement implies commitment: When B has been entitled by A to drink a beer from the six-pack, $\mathrm{A}$ is committed to let $\mathrm{B}$ take and drink the beer. Used in this way, 'to share' refers to the act of making a resource actually available (cutting, dividing, inviting a friend in) as well as to the moral implications: the entitlement or commitment. The concepts of entitlement and commitment are complementary.

By virtue of this logic, the term 'shared' is also used in a domain of discourse or 'language game' quite different from that of dividing six-packs and giving access to fridges. For example, when participants at a design meeting, after a lengthy discussion about some open design issues, at the end of the meeting agree on a proposed solution and action plan, they might refer to what has been achieved as a 'shared understanding' of what to do now. What they mean by that is $(a)$ that they are all committed: they have had their say and can be justifiably held accountable; and $(b)$ that they are supposed to know what to do without having yet another meeting and if they do not know, then it is perhaps because 
they have not paid attention at the meeting. That is, the issue is closed; there is or should be no serious doubt or uncertainty. A 'shared understanding' here simply means: it is unproblematic to proceed.

We talk about 'a shared goal' or 'a shared language' or 'shared information' or 'shared knowledge' in much the same way. Thus 'a shared goal' is an aim, a destination, an outcome, etc. that has been negotiated, articulated, agreed upon, etc., so that everybody can go on with their individual tasks while taking for granted, for the time being and until further notice, that the others will do likewise. When we refer to a 'shared goal' it simply means that we can all be held accountable. We say that we have a 'shared language' when we can engage in conversation and exchange emails and read scholarly articles while expecting that we do not have to be guessing incessantly at what is being said or be asked constantly for clarification or explanation. We can similarly 'share' information in the sense that we disclose what we have heard or seen in a such a way that all those to whom it has been disseminated can be presumed to be aware of it, and if somebody then is not aware of it, then that somebody may justifiably be considered inattentive, negligent, or plain dumb. We can also be said to 'share' a body of knowledge when we can justifiably presume, for instance from the fact that others have taken the same academic degree or belong to the same profession, that they understand the background of a statement, the implications of some issue, or are able to perform relevant tasks, and so on.

In these language games, 'sharing' is not about partitioning a thing such as a cake and handing out the portions or about dividing up a sum of money or about granting others rightful access to resources such as tool magazines, fridges, or beds. We are rather expressing our justifiable confidence that action will be performed in an orderly way without need for further negotiation, clarification, explanation, etc. It means: we are each of us justified in proceeding as normal. These extensions of the notion of 'sharing' all trade in the grammar of the complementary concepts of entitlement and commitment; that is, they all hinge on justifiable normative expectation.

In short, the word 'shared' is used in a widely ramified family of metaphors. In ordinary usage, the different uses of the term 'shared' in domains of discourse as different as those of 'shared beds' or 'shared goals' do not pose a problem at all. The problem emerges as soon as we talk about 'sharing' outside of the practical contexts of ordinary life from which the picture is derived.

For instance, whereas uses of the adjective 'shared' such as 'shared goal', etc. trade in the grammar of entitlement and commitment, they also, by virtue of the very word 'shared', retain the connotation of a useful and tangible resource such as cakes and beer or fridges and beds of which we expect causal power: satisfy hunger, quench thirst, support the weary body. But here the connoted picture may play a trick on us. What we say is 'shared' (such as a 'goal') may, by analogy to beer and fridge, acquire the aura of something tangible that can serve as a causal factor: orderly accomplishment of cooperative activities is possible because of a 'shared goal', a 'shared understanding', 'shared situation awareness', and what 
have you. Then the notion of a 'shared goal' suddenly becomes assimilated to the notion of a 'shared resource': something that exists out there, some ghostlike 'internal entity' or agency that makes us to conduct our business in an orderly manner.

Moreover, the adjective 'shared' is sometimes used as a somewhat sloppy way of expressing common attributes (e.g., 'shared view', 'shared habit', or 'shared hair color'). In this usage, nobody has been granted right of possession, nor has anybody been assured of justifiable expectations. It is used in the distributive sense: it applies to each but not to any relationship between them. This usage has severed the connections to the original and the extended metaphors. Again, in daily conversation, this normally does not pose any serious problems, but in analytic discourse, where abstraction from context is required, it may very well give rise to misunderstandings and it certainly causes trouble when the word 'shared', with all the connotations associated with its widely ramified family of metaphorical use, is used in the construction of a conceptualization, or theory even, of the enormous scope intended by Tomasello.

Thus, when Tomasello (2009) uses 'share' in expressions such as 'share the catch' with outsiders, hunters' 'sharing spoils' among themselves, or in general 'sharing resources such as food', we are on firm ground: this is at the center of the ordinary use of the term. On the other hand, when Tomasello as well as Tenenberg et al. use expressions such as 'shared context' it is not at all clear what is meant by 'shared'. Similarly, and more pertinent to the issue at hand, when Tomasello and his colleagues use the term 'shared' in expressions like 'shared goal' or 'shared intentionality', it is not always quite clear what work 'shared' does. Does it refer to observable acts where actors enter into relations of justifiable expectations, such as when at the end of a meeting the chairperson asks 'Are we in agreement about this?' and the participants all nod or shake hands? If so, it is sufficiently clear. But when workers are engaged in a large-scale cooperative effort such as (to mention one of the examples Tomasello uses) building a house, it becomes very unclear indeed. In fact, the workers may not even meet each other in the course of the project, the workmen building the foundation having finished long before painters and electricians and painters even arrive on the site? In which sense of 'shared' can they then said to have 'shared intentionality'? By having signed a contract, perhaps with different firms, that in turn are contracted to do various work at the site? By working according to the same architectural plans? By being ascribed the common attribute of working at the same site?

Or, if Tomasello's reference to the building of a house as an example of 'collaborative activities' is not really pertinent, in view of the thrust of his reasoning, what is then the scope of the notion 'shared intentionality'? It is supposed to be at the root of human sociality (culture, institutions, the works), and yet it seems difficult to make sense of what it means when applied to an ordinary case of cooperative work. Anyway, its scope seems to drastically restricted to what is really an ideal type situation. For Tenenberg et al. (§3) state quite clearly 
that Bratman (1992, p. 327) 'makes explicit the conditions for shared intentionality' when he stipulates 'a trio of features characteristic' of 'shared cooperative activity', which Tomasello et al. then summarize as follows:

'(1) the interactants are mutually responsive to one another, (2) there is a shared goal in the sense that each participant has the goal that we (in mutual knowledge) do X together, and (3) the participants coordinate their plans of action and intentions some way down the hierarchy which requires that both participants understand both roles of the interaction (role reversal) and so can at least potentially help the other with his role if needed.' (Tomasello et al. 2005, p. $680)$.

If the scope of the applicability of 'shared intentionality' is restricted to settings with such characteristics, one might find examples in modern industrial society but one would have to look hard and wide.

Finally, let us go back to Tomasello's notions of 'shared goal' and 'shared intentionality'. As noted above, it is a marker for the intellectualist legend that its argument ends in infinite regress. It does not explain what it purports to explain and is therefore empirically impotent. This is also the case with Tomasello's attempt to explain orderly conduct in cooperative activities by means of the notion of 'shared intentionality'. How do we test this thesis? How do we determine, empirically, that $\mathrm{A}$ and $\mathrm{B}$ in actual fact accomplish their cooperative effort in an orderly way by virtue of 'shared intentionality'? The answer is that the only method available is that of observing whether they in fact do manage to conduct themselves in an orderly fashion and accomplish what they are supposed to accomplish with the resources available. But that is exactly what should be explained! To say that their ability to cooperate is due to their 'shared intentionality' is merely substituting one expression of the explanandum for another and then to offer that as the explanans. It is like explaining that a man behaves cleverly by referring to his 'intelligence' or that certain people conduct themselves in a certain way because of their 'culture'. As noted above, substituting one description of the phenomenon to be explained for another description is not an explanation. It is just a circular argument. For an explanation to have scientific merit, it must be possible to investigate the explanans independently of the explanandum. More than that, if 'shared intentionality' or something similar is required for orderly performed cooperative work to be possible, which conclusions can then be inferred from situations of failure, cockup, breakdown, misunderstanding, etc.? That the workers did not have 'a shared intentionality' after all? But if they later the same day, after lunch, say, perform in their usual smooth way, would that then mean that the 'shared intentionality' for some reason was temporarily absent, like a transient power failure? Similarly, does the fact that a misunderstanding occurs in a given conversation indicate that the interlocutors did not have a 'shared language' after all, or just that they, well, misunderstood each other? As an explanatory construct, the invocation of some presumed 'shared' mental entity such as 'intentionality' is vacuous. Worse, it makes us stop our investigations into actual practices before we even begin! 


\title{
3.4 'Common ground', firm ground?
}

It is noteworthy that Tomasello himself is aware of the problem of infinite regress, or 'infinite recursion' as he calls it (2008, pp. 74, 77, 94 f., 188; 2009, p. 69), as are Tenenberg et al. ( $(3)$. Both teams of authors also obviously believe that Herbert Clark in his theory of 'common ground' showed a way out of infinite regress.

This is Clark and Brennan's account of the problem and the solution to the problem (and I quote at length again):

\begin{abstract}
'All collective actions are built on common ground and its accumulation. [9] Communication, of course, is a collective activity of the first order. When Alan speaks to Barbara, he must do more than merely plan and issue utterances, and she must do more than just listen and understand. They have to coordinate on content (Grice 1975, 1978). When Alan refers to "my dogs," the two of them must reach the mutual belief that he is referring to his feet. They must also coordinate on process. Speech is evanescent, and so Alan must try to speak only when he thinks Barbara is attending to, hearing, and trying to understand what he is saying, and she must guide him by giving him evidence that she is doing just this. Accomplishing this, once again, requires the two of them to keep track of their common ground and its moment-bymoment changes. [J] In communication, common ground cannot be properly updated without a process we shall call grounding [...]. In conversation, for example, the participants try to establish that what has been said has been understood. In our terminology, they try to ground what has been said - that is, make it part of their common ground. But how they do this changes a great deal from one situation to the next. Grounding takes one shape in face-to-face conversation but another in personal letters. It takes one shape in casual gossip but another in calls to directory assistance. [...] What does it take to contribute to conversation? Suppose Alan utters to Barbara, "Do you and your husband have a car?" In the standard view of speech acts [...], what Alan has done is ask Barbara whether she and her husband have a car, and, in this way, he has earned the conversation forward. (Clark and Brennan 1991, p. 128)
\end{abstract}

'But', they object, 'this isn't quite right', for asking 'a question requires more than uttering an interrogative sentence. It must also be established that the respondent has understood what the questioner meant' (Clark and Brennan 1991, pp. $128 \mathrm{f}$.).

As always with the intellectualist legend, this (highly intellectualized) account is heading directly towards the wetlands of infinite regress, for the respondent's response (a nod, a 'Hmm', a 'Go on') also has to be understood and acknowledged by the speaker. And so on. Infinite regress is looming. But Clark and Brennan have a solution (based on Clark and Schaefer 1987):

'[1] Of course, understanding can never be perfect. [2] We assume that the criterion people try to reach in conversation is as follows [...]: [3] The contributor and his or her partners mutually believe that the partners have understood what the contributor meant[,] to a criterion sufficient for current purposes. [4] This is called the grounding criterion. [5] Technically, then, grounding is the collective process by which the participants try to reach this mutual belief.' (Clark and Brennan 1991, p. 129.). ${ }^{6}$

\footnotetext{
6 The comma in brackets is inserted by me. - The expression 'to criterion' seems to be experimentalist jargon (e.g., 'trial to criterion'). It is used in the context of experiments in which a test is conducted to produce values on a range with a predefined satisfaction value ('criterion'). When Clark and Brennan use it
} 
The first sentence (\#1) is of course pure metaphysics, for it is unintelligible to talk about 'perfection' in the abstract, without a criterion according to which something is deemed 'perfect' (or not). So, what is the criterion of 'perfect' understanding? The authors thus wisely hasten to introduce (in \#2) the notion of 'criterion'. Their solution is that actors, in order to get the job done and get on with their lives, avoid infinite regress by cutting the regression short when they, according to what is 'sufficient for current purposes', mutually believe that their partners have understood their respective contributions (\#3 and \#4). Now, are the 'current purposes' not supposed to be settled (continually) as part of the recursive process of establishing mutual understanding? How do they know which purpose each other is striving to achieve and what would satisfy it? How does A know that B knows that A is working towards the same purpose, and so on? That is, the interlocutors avoid infinite regress because they, Clark and Brennan assume, are already in agreement about 'current purposes' and its use as a criterion. That is, the 'mutual belief' they are said to 'reach' in the 'collective process' is there from the beginning! In short, infinite regress is avoided because it is ruled out in advance. As Clark and Brennan, inadvertently perhaps, put it themselves: the 'purpose' 'shapes' the conversation (p. 128). In sum, the ensuing order was there from the very beginning: they have a 'shared purpose' and also a 'shared' way of using that as 'criterion'. This solution is a scam. The notion of 'common ground' does not avoid the morass of infinite regress and thus accounts for nothing.

This also makes the entire conception of 'shared intentionality' based on 'socially recursive inference', which explicitly hinges on Clark's solution to the problem of 'infinite regress', come tumbling down.

At this point it is in its place to point out that the conception of 'shared intentionality as developed by Tomasello et al. and further developed by Tenenberg et al. is in direct contradiction of Searle's argument. As noted above, Searle basically argued that we do and can talk about 'collective intention' simply because for this to be intelligible it is enough that actors take for granted that the others, who supposedly are involved in the activity, indeed are. In fact, Searle explicitly argues that the argument later developed by Tomasello et al. (and, by implication, Tenenberg et al. too) is fatally flawed. 'We are tempted', he warns, "to construe "doing his part" to mean doing his part toward achieving the collective goal.' This is exactly and explicitly what Tomasello et al. do. 'But', Searle goes on:

"if we adopt that move, then we have included the notion of a collective intention in the notion of "doing his part". We are thus faced with a dilemma: if we include the notion of collective intention in the notion of "doing his part", the analysis fails because of circularity; we would now be defining we-intentions in terms of we-intentions.' (Searle 1990).

('to a criterion sufficient for current purposes') they seem to be using it in that sense. That is, they are in the extremely intellectualist business of portraying conversationalists as experimental scientists trying to 'reach... criterion'. 
The hopeful invocation of Clark's solution fails. As Searle sums it up: 'The problem with believing that you believe that I believe, etc., and you believing that I believe that you believe, etc., is that it does not add up to a sense of collectivity' (Searle 1995, p. 24). Instead of accounting for collectivity, it ends in infinite regress. Tomasello et al. are, if I may, whipping a dead horse. I am afraid that Tenenberg and his colleagues are too.

Let us look again at the passage from Clark and Brennan: A, it is said, 'must do more than merely plan and issue utterances', and B 'must do more than just listen and understand', they 'have to coordinate', they 'must reach the mutual belief', etc. Where does this 'must' come from? Is it like the 'must' that tells us that $2+2$ $=4$ ? Is it the 'must' of an urge? Is it the 'must' of a rule the two persons recognize and feel obliged to obey? Or is it, as I submit, a 'must' that Clark et al. presume (must presume?) in order to make their examples (from the 'Lund corpus' of decontextualized snippets of conversation collected by Svartvik and Quirk 1980)) fit into a pre-established linguistic machinery? Similarly, is it at all appropriate to talk about 'beliefs', as Clark and Brennan do here? When actors in their ongoing activities take for granted that the world will exist tomorrow or even in a minute, is that a 'belief'? When I open a can of beer, do I then 'believe' that it contains beer and that it will quench my thirst? Or is that not rather yet another intellectualist imputation? Can one, indeed, legitimately ascribe 'beliefs' to actors at will, impute endless chains of 'beliefs', in the construal of a philosophical or psycholinguistic account? As suggested by Julia Tanney (2013), we normally only retreat from an ordinary description of an actor's conduct to the ascription of beliefs 'when her action cannot be given the normal justification'. It seems as if this entire tradition, from Grice to Clark to Tomasello, grants itself a license to impute 'beliefs' as liberal as the one psychoanalysis assigned to itself a century or so ago.

If we, finally, step back from the machinery of this (unfortunately rather long and intricate line of argument) and look back, what we see is an account of those interactions whereby order is produced and maintained that is highly intellectualized: actors are depicted as something akin to philosophers of language engaged in making 'recursive inferences' from 'beliefs' based on 'evidence' according to some ethereal but supposedly unforgivingly rigid linguistic machinery. The intellectualist legend is alive and well.

\section{5 'Cooperation', or false ground}

A common but disconcerting characteristic of the literature on 'collective intentionality', 'shared intentionality', and 'common ground' is that authors, more often than not, play fast and loose with the notion of 'cooperation'. This in particular applies to Tomasello et al.

In our everyday conduct, we can say to a person, with a dose of sarcasm, 'You're not very cooperative, now, are you?', in the hope that he will stop pursuing his own ideas or interests and be 'a good chap', a 'team player', a' 
comrade'. In social reform movements, it has been used to express the idea of 'mutual help' and, in a related sense, as a label for the 'cooperative' movements of peasants, workers, or consumers based on common property and profit sharing. In anthropology, the term is used in the sense of 'mutual help', sometimes in the form of the sharing of food, especially meat, sometimes also in the sense of sharing property and outcome, but also in a wider sense of consensual attitudes and sentiments. Again, this ordinarily does not cause confusion.

However, a somewhat related notion is invoked by the term 'cooperation' in evolutionary biology and ethology, where it is generally used for behavior of organisms that cannot (easily) be understood in terms of competition or conflict and that, from the point of view of evolutionary theory and the underlying notion of 'survival of the fittest', seems paradoxical. In economics, 'cooperation' is often used in the sense of collusion or absence of competition. In game theory, this notion has been further abstracted to mean the striking and upholding of alliances (for mutual benefit), as in the famous 'prisoners' dilemma' case, in which prisoners are faced with the option of 'cooperating' with each other by clamming up. Interestingly, in ordinary language 'cooperation' can also mean the opposite, namely a delinquent's 'cooperating' with the prosecutor by betraying his accomplishes or a prisoner's 'cooperating' with his jailor with a view to improving his conditions or a member of a nation under occupation 'cooperating' with the oppressors, a so-called 'collaborator'.

The term is also used in an even more abstract sense in philosophical social linguistics such as in the work of Paul Grice, whose thinking has influenced the notion of 'shared intentionality' significantly. Thus, observing that our 'talk exchanges do not normally consist of a succession of disconnected remarks, and would not be rational if they did', Grice suggested a ('rough') 'Cooperative Principle' that putatively regulates all (rational) talk, and which 'participants will be expected (ceteris paribus) to observe, namely: Make your conversational contribution such as is required, at the stage at which it occurs, by the accepted purpose or direction of the talk exchange in which you are engaged' (Grice 1975). Here 'cooperation' is extended to refer to just about any manifestation of social order, including, perversely, somebody's obeying a thug's demand to hand over the wallet or a slave laborer's submission to a work regime that is bound to ruin his health and probably cause his death within months (as in the labor camps of the 20th century). In fact, while 'cooperation' in ordinary discourse typically and formally expressed, means the voluntary suppression of self-interest for the benefit of other members of the collective or the collective as a whole, 'cooperation' sometimes simply means suppression of competition and conflict tout court, irrespective of volition or motive. One will find a similar apologetic use of the term 'cooperation' in managerialist philosophy, for example, when the contractual relationship between factory owner and (formally free) wage worker is couched as 'cooperation' defined by some 'shared goal': the deceitful picture of master and underling pulling together. 
While this may leave the impression that the various authors - Grice, Tomasello, and Clark in particular - are developing theories of dizzying scope, they are, as far as their talking about 'cooperation' is concerned, just stretching the use of a term far beyond its breaking point.

\section{Moving to higher ground}

Now, what are the implications of all this for design, and for CSCW. Let us begin with the analysis of the peer programming case offered by Tenenberg et al. According to the analysis, each of the two programmers, Hank and Danny, not only needs to take into account what is displayed on the screens and the orientation of the other's body relative to the two screens; each of them also needs to, and does, take into account that the other is able to take, and has taken, into account both what has been displayed and what has been taken into account by the other.

On the basis of the evidence Tenenberg et al. have so meticulously presented, I find this analysis quite plausible. But when they add that this goes on ' $a d$ infinitum' (and do so repeatedly), their claim is of course no longer grounded in evidence (how could it be?). As argued earlier in this commentary, infinite regress is the emblem of the intellectualist legend and shows that its explanations are vacuous. That Tenenberg et al. do not try to hide that their account ends in infinite regress but instead wear it proudly for all to see may be seen as commendable, but it is rather an attempt to make a virtue of a vice.

But leaving this issue aside, what lessons can we take from this case? Indeed, what $i s$ the case? It is of course a case of programming and accordingly design work; that is, programmers deal with what Horst Rittel and Melvin Webber famously described as a 'wicked problem':

\footnotetext{
'in order to describe a wicked problem in sufficient detail, one has to develop an exhaustive inventory of all conceivable solutions ahead of time. The reason is that every question asking for additional information depends upon the understanding of the problem - and its resolution - at that time. Problem understanding and problem resolution are concomitant to each other.' Furthermore, 'the process of solving the problem is identical with the process of understanding its nature, because there are no criteria for sufficient understanding and because there are no ends to the causal chains that link interacting open systems, the would-be planner can always try to do better.' (Rittel and Webber 1973,pp. 161 f.)
}

These complexities are compounded when solving a 'wicked problem' involves multiple actors, as different aspects of the problem are addressed by different designers and as interdependencies among these aspects, and hence between the actors, emerge and change as the design project unfolds (Schmidt 1998a). And on top of all that, software design is cooperative design work of a very special kind, in that the representation of the design, the source code, is textual (as opposed to for instance a drawing or a model), and that it therefore is difficult even for highly skilled workers to reckon from reading the code what the 
designed object is and how it will behave when compiled, launched, and running on a computer. For as pointed out by the renowned Frederick Brooks:

'In spite of progress in restricting and simplifying the structures of software, they remain inherently unvisualizable, thus depriving the mind of some of its most powerful conceptual tools. This lack not only impedes the process of design within one mind, it severely hinders communication among minds.' (Brooks 1987, pp. 185 f.).

This 'unvisualizability' of the object of work, the program under construction, is a, if not the, fundamental challenge for the practices of programming. To deal with this, practitioners have developed a vast repertoire of techniques, from flowcharts to rapid prototyping to agile software development.

In pair programming, as in the case at hand, one programmer produces the code while the other reviews the quality of the code as it is being produced. That is, the two of them are engaged in two different aspects of the task or in two different but interdependent tasks: coding and reviewing. And while working with something as unvisualizable as code, by means of two screens and keyboards, their work is temporally tightly coupled, as the authors point out. They thus need to stay fully attuned to each other's activities. However, the mutual attunement is hampered by the interruption of the continuity of the task performance and the staff change mid-course, imposed by the idiosyncratic version of the pairprogramming regime of the setting. What we are presented with is a situation where a particular programming task has been interrupted and then resumed but with new staffing, in that Simon is replaced by Danny while Hank continues the task from where it was interrupted. Consequently, it requires considerable alignment work in order for Danny to be able to understand what the task is and what is to be done. Given these circumstances, it seems pertinent to say that each of them needs to take into account that the other takes into account both what has been displayed and what has been taken into account by the other. So far we are on common and firm ground. But is this constitutive of cooperative work? Surely not. In many cooperative work settings even time-critical work conducted in a distributed manner is accomplished in an orderly fashion and without actors' being able to see each other or speak to each other (for the classical study of cooperative operation of a hot rolling mill, cf. Popitz et al. 1957). ${ }^{7}$ In complex cooperative work settings such as manufacturing, health care, transportation, construction, and so on, coordination is typically performed without continuous alignment of intentions and plans. On the other hand, of course, something like 'socially recursive intentionality', or ongoing mutual confirmation or adjustment of intention (direction of action, action plan, etc.), may be a routine occurrence in certain settings, as in the case at hand, and may be a phenomenon we find from time to time in cooperative work setting in general, the reason being that, every now and then, there are, unavoidably, situations in cooperative activities where workers are in doubt about what to do.

\footnotetext{
${ }^{7}$ For an English, summary, see my Modes and Mechanisms (Schmidt 1994b; For observations of highly distributed coordination of time-critical work in a steel plant, cf. Schmidt 1998b).
} 
This is uncontroversial. What is controversial is the status of the notion of 'awareness' in CSCW. At least, it seems to be the utter lack of clarity about this notion that is the source of the present controversy.

The problem, is, first of all, that we, by using the term 'awareness', have been using an attention concept for what is best characterized as heeding (as argued in Schmidt 2011, pp. 24 ff.). That in itself has caused immense confusion. But what seems clear to me, by now, is that we have been groping for air all along, in as much as, so it seems, discourse has proceeded on the assumption that 'awareness' is a distinct phenomenon, even a 'practice'. For example, I argued in 2002 that 'it is becoming increasingly clear that the term "awareness" does not denote a set of related practices'. I accordingly argued that 'awareness' is an 'integrated aspect of practice and must be investigated as such' and that 'we cannot talk of awareness as an separate entity but only as somebody's being aware of some particular occurrence and thus only with reference to certain practices of which being aware of something is an aspect' (2002a, p. 287 f.). However, in open contradiction of that insight, I still continued to talk about 'awareness practices' or referring to 'awareness' as a category of 'coordinative practices' (2002a, pp. 291 f.; 2011, pp. 351-355). Perhaps the very label 'mutual awareness' tempts us to presume that there is a common kernel of behavior we refer to by the label 'mutual awareness'. Some would say that it reifies these elusive behavioral characteristics. Or to put it differently, the label makes us search for that kernel instead of analyzing the practices to which these elusive behavioral characteristics belong.

As Ryle (1949, pp. 29 ff.) reminds us in his critique of the intellectualist legend, to do something well is not doing two things (doing it and meeting criteria of quality) but rather doing something in a certain way. It would make no sense to make 'well-ness' a topic of research. Similarly, to say that something is done in a timely manner or done carefully would not tempt us to study timeliness or carefulness as distinct phenomena. The same applies to doing something attentively, heedfully, or in awareness of what is going on in the context.

'Awareness', then, is not a distinct and researchable phenomenon; nor is 'heeding'. Discussing it as if it is, as it has been done over the years, is therefore a source of utter confusion. Instead of analyzing the work practices in their rich complexity (working skills and routines, strategies for identifying and dealing with contingencies, coordinative practices, and in that context and on that background the cues skilled practitioners heed), it tempts us to reduce the analytic task to that of trying to identify commonalties across practices in terms of contingent means or techniques. (On the concept of 'practice', cf. Schmidt 2014).

That said, it is obvious that the 'awareness' discourse has a rational motivation. It has been driven by the challenges of designing collaboration technologies for real-time interaction in small groups (collaborative editing, collaborative drawing, collaborating in 'media spaces', collaborating in 'virtual environments' or in 'augmented reality'), which is a special but also important research problem in CSCW. The notion of 'awareness' can here be said to have served as a proxy for the family of issues addressed in the subarea devoted to this. But by virtue of this, 
it has also been used as a way to express the various research problems as instances of a presumptively general one, namely that of 'small group interaction'. However, to take the case presented by Tenenberg et al., what is it that Danny and Hank monitor for in their work and, as part of that, in making sense of what the other is up to? Tenenberg et al. seem satisfied to note that Hank and Danny 'are mutually oriented to on the computer display', that Danny 'gazes at the computer displays for several seconds', that Hank 'points to left display with index finger', that Hank and Danny 'glancing every second or two at one of the computer displays', and that 'the most important heeding strategy is to see the computer display and where the other person is oriented at the same time' ( $\S$ 4.3.1-4.3.3 and 5.1). However, such description reduces intentional action, or the performance of a practice, to an account in terms of bodily conduct. It is a very thin description indeed. To understand the practice in question, and I would like to add: to make technological progress on this front, we need to identify practitioners' 'typifications'; in this case, the categories in which they distinguish displayed source code into what is important and what is not, the specific configurations of text that is taken to be significant, etc. Only by doing so, can we abstract from existing techniques (or means) and begin to devise alternative ones.

In sum, it may be more productive not to think of this in terms of generic 'small group interaction', not to mention 'awareness', but in terms of the specific practices members engage in: engineering design, programming, accounting, etc. For not only are their perceptual skills different, they see differently, their typifications are different, they have distinctly different priorities and success criteria, etc. In other words, they exemplify very different cooperative work practices that just happen to have in common that they often are performed in 'small groups'. In short, also in this area of CSCW do we have to study actual work practices in their rich complexity. ${ }^{8}$

\section{References}

Anscombe, Gertrude Elizabeth Margaret (1957). Intention. Cambridge: Basil Blackwell. (Second ed., 1963). - Cambridge, Mass., and London: Harvard University Press, 2000 (Paperback ed.).

Bratman, Michael E. (1989). Intention and personal policies. In J. E. Tomberlin (ed.): Philosophical Perspectives. Vol. 3, Philosophy of Mind and Action Theory. Atascadero, Calif.: Ridgeview Publishing Company, pp. 443-469. 10.2307/2214277.

Bratman, Michael E. (1992). Shared cooperative activity. The Philosophical Review. Vol. 101, no. 2, April 1992, pp. 327-341.

Bratman, Michael E. (1993). Shared intention. Ethics. Vol. 104, no. 1, October 1993, pp. 97-113.

Brooks, Frederick P., Jr. (1987). No silver bullet: Essence and accidents of software engineering. (Computer). In F. P. Brooks, Jr.: The Mythical Man-Month: Essays on Software Engineering. Reading, Mass.: Addison-Wesley, 1995, pp. 177-203.

\footnotetext{
8 The research underlying this commentary has been supported by the Velux Foundation under the 'Computational Artifacts' project.
} 
Clark, Herbert H.; and Edward F. Schaefer (1987). Collaborating on contributions to conversations. Language and Cognitive Processes. Vol. 2, no. 1, 1987, pp. 19-41.

Clark, Herbert H.; and Susan E. Brennan (1991). Grounding in communication. In L. B. Resnick; J. M. Levine; and S. D. Teasley (eds.): Perspectives on Socially Shared Cognition. Washington, DC: American Psychological Association, pp. 127-149.

Crone, Patricia (1989). Pre-Industrial Societies: Anatomy of the Pre-Modern World. London: Oneworld Publications. (3rd ed., 2015).

Dewan, Prasun; and Rajiv Choudhary (1991). Primitives for programming multiuser-user interfaces. In J. R. Rhyne (ed.): UIST'91: Fourth Annual Symposium on User Interface Software and Technology, South Carolina, USA, 11-13 November 1991. New York: ACM Press, pp. 69-78.

Dourish, Paul; and Victoria Bellotti (1992). Awareness and coordination in shared workspaces. In M. M. Mantei; R. M. Baecker; and R. E. Kraut (eds.): CSCW'92: Proceedings of the Conference on Computer-Supported Cooperative Work, 31 October-4 November 1992, Toronto, Canada. New York: ACM Press, pp. 107-114.

Dourish, Paul; and Sara Bly (1992). Portholes: supporting awareness in a distributed work group. In P. Bauersfeld; J. Bennett; and G. Lynch (eds.): CHI'92 Conference Proceedings: ACM Conference on Human Factors in Computing Systems, 3-7 May 1992, Monterey, California. New York: ACM Press, pp. 541-547.

Endsley, Mica R; R. John Hansman; and Todd C. Farley (1999). Shared situation awareness in the flight deck-ATC system. IEEE Aerospace and Electronic Systems Magazine. Vol. 14, no. 8, August 1999, pp. 25-30.

Endsley, Mica R. (1995). Towards a theory of situation awareness in dynamic systems. Human Factors. Vol. 37, no. 1, March 1995, pp. 32-64.

Endsley, Mica R.; and William M. Jones (2001). A model of inter- and intrateam situation awareness: Implications for design. training, and measurement. In M. McNeese; E. Salas; and M. R. Endsley (eds.): New Trends in Cooperative Activities: Understanding System Dynamics in Complex Environments. Santa Monica, Calif.: Human Factors and Ergonomics Society, pp. 46-67.

Gilbert, Margaret (1992). On Social Facts. Princeton, New Jersey: Princeton University Press.

Grice, H. Paul (1975). Logic and conversation. In P. Cole and J. L. Morgan (eds.): Syntax and Semantics. Volume 3: Speech Acts. New York: Academic Press, pp. 41-58.

Grice, H. Paul (1978). Some further notes on logic and conversation. In P. Cole and J. L. Morgan (eds.): Syntax and Semantics. Volume 9: Pragmatics. New York: Academic Press, pp. 113-128.

Harper, Richard H. R.; John A. Hughes; and Dan Z. Shapiro (1989). The Functionality of Flight Strips in ATC Work: The report for the Civil Aviation Authority. Lancaster, U.K.: Lancaster Sociotechnics Group, Department of Sociology, Lancaster University, January 1989.

Harper, Richard H. R.; and John A. Hughes (1993). What a f-ing system! Send 'em all to the same place and then expect us to stop 'em hitting: Managing technology work in air traffic control. In G. Button (ed.): Technology in Working Order: Studies of Work, Interaction, and Technology. London and New York: Routledge, pp. 127-144.

Heath, Christian C.; and Paul Luff (1992). Collaboration and control: Crisis management and multimedia technology in London Underground control rooms. Computer Supported Cooperative Work (CSCW). Vol. 1, no. 1-2, March 1992 [published September 1992], pp. 6994.

Heath, Christian C.; Marina Jirotka; Paul Luff; and Jon Hindmarsh (1993). Unpacking collaboration: The interactional organisation of trading in a City dealing room. In G. De Michelis; C. Simone; and K. Schmidt (eds.): ECSCW'93: Proceedings of the Third European Conference on Computer-Supported Cooperative Work, 13-17 September 1993, Milano, Italy. Dordrecht: Kluwer Academic Publishers, pp. 155-170. 
Heath, Christian C.; and Paul Luff (2000). Technology in Action. Cambridge: Cambridge University Press.

Heath, Christian C.; Marcus Sanchez Svensson; Jon Hindmarsh; Paul Luff; and Dirk Vom Lehn (2002). Configuring awareness. Computer Supported Cooperative Work (CSCW). Vol. 11, no. 3-4, September 2002, pp. 317-347.

Johnson, Allen W.; and Timothy Earle (1987). The Evolution of Human Societies: From Foraging Group to Agrarian State. Stanford, Calif.: Stanford University Press.

Kenny, Anthony (1971). The homunculus fallacy. (Interpretations of Life and Mind, M. Grene (ed.). London: Routledge \& Kegan Paul). In A. Kenny: The Legacy of Wittgenstein. Oxford: Basil Blackwell, 1984, pp. 125-136.

Lauwers, J. Chris; and Keith A. Lantz (1990). Collaboration awareness in support of collaboration transparency: Requirements for the next generation of shared window systems. In J. C. Chew and J. Whiteside (eds.): CHI'90 Conference Proceedings: ACM SIGCHI Conference on Human Factors in Computing Systems, Seattle, Washington, 1-5 April 1990. New York, N.Y.: ACM Press, pp. 303-311.

Lee, Richard Borshay; and Irven DeVore (eds.) (1968). Man the Hunter. Chicago: Aldine.

Nardi, Bonnie A.; Steve Whittaker; and Erin Bradner (2000). Interaction and outeraction: Instant messaging in action. In W. A. Kellogg and S. Whittaker (eds.): CSCW 2000: ACM Conference on Computer Supported Cooperative Work, 2-6 December 2000, Philadelphia, Pennsylvania, USA. New York: ACM Press, pp. 79-88.

Popitz, Heinrich; Hans Paul Bahrdt; Ernst A. Jüres; and Hanno Kesting (1957). Technik und Industriearbeit: Soziologische Untersuchungen in der Hüttenindustrie. Tübingen: J. C. B. Mohr.

Rittel, Horst W. J.; and Melvin M. Webber (1973). Dilemmas in a general theory of planning. Policy Sciences. Vol. 4, 1973, pp. 155-169.

Rösener, Werner (1985). Peasants in the Middle Ages. Urbana and Chicago: University of Illinois Press, 1992. Transl. from Bauern im Mittelalter, München: C. H. Beck, 1985. Transl. by A. Stützer.

Ryle, Gilbert (1949). The Concept of Mind. London: Hutchinson's University Library.

Ryle, Gilbert (1966-67). Thinking and reflecting. (Royal Institute of Philosophy Lectures). In G. Ryle: Collected Papers. Volume II: Collected Essays, 1929-1968. London: Hutchinson \& Co, 1971, pp. 465-479.

Ryle, Gilbert (1968). The thinking of thoughts: What is "le Penseur" doing? (University Lectures, University of Saskatchewan). In G. Ryle: Collected Papers. Volume II: Collected Essays, 1929-1968. London: Hutchinson \& Co, 1971, pp. 480-496.

Schmidt, Kjeld; and Liam J. Bannon (1992). Taking CSCW seriously: Supporting articulation work. Computer Supported Cooperative Work (CSCW). Vol. 1, no. 1-2, March 1992 [published September 1992], pp. 7-40.

Schmidt, Kjeld (1994a). Cooperative work and its articulation: Requirements for computer support. Travail Humain. Vol. 57, no. 4, December 1994, pp. 345-366.

Schmidt, Kjeld (1994b). Modes and Mechanisms of Interaction in Cooperative Work. Roskilde, Denmark: Risø National Laboratory, March 1994. - Risø-R-666(EN).

Schmidt, Kjeld (1998a). Cooperative design: Prospects for CSCW in design. Journal of Design Sciences and Technology. Vol. 6, no. 2, 1998, pp. 5-18.

Schmidt, Kjeld (1998b). Some notes on mutual awareness. [Memorandum for EU TMR Project COTCOS. Manuscript]. Copenhagen, 1998. $<$ http://cscw.dk/schmidt/papers/mutual_awareness.pdf $>$ 
Schmidt, Kjeld; and Carla Simone (2000). Mind the gap! Towards a unified view of CSCW. In R. Dieng, et al. (eds.): Designing Cooperative Systems: The Use of Theories and Models. Proceedings of the 4th International Conference on the Design of Cooperative Systems (COOP 2000) [23-26 May 2000, Sophia Antipolis, France]. Amsterdam etc.: IOS Press, pp. 205-221.

Schmidt, Kjeld (2002a). The problem with "awareness": Introductory remarks on "Awareness in CSCW". Computer Supported Cooperative Work (CSCW). Vol. 11, no. 3-4, September 2002, pp. 285-298. - [Also in K. Schmidt: Cooperative Work and Coordinative Practices, London: Springer, 2011 (Chapter 8)].

Schmidt, Kjeld (2002b). Remarks on the complexity of cooperative work. (Revue des sciences et technologies de l'information. Série Revue d'intelligence artificielle (RSTI-RAI), 2002). In K. Schmidt: Cooperative Work and Coordinative Practices: Contributions to the Conceptual Foundations of Computer-Supported Cooperative Work (CSCW). London: Springer, 2011, pp. 167-200.

Schmidt, Kjeld (2011). Cooperative Work and Coordinative Practices: Contributions to the Conceptual Foundations of Computer-Supported Cooperative Work (CSCW). London: Springer.

Schmidt, Kjeld (2014). The concept of 'practice': What's the point? In C. Rossitto, et al. (eds.): COOP 2014: Proceedings of the 11th International Conference on the Design of Cooperative Systems, 27-30 May 2014, Nice, France. London: Springer, pp. 427-444.

Schweikard, David P.; and Hans Bernhard Schmid (2013). Collective intentionality. The Stanford Encyclopedia of Philosophy. 13 June 2013. Summer 2013 Edition. $<$ http://plato.stanford.edu/archives/sum2013/entries/collective-intentionality/>

Searle, John R. (1990). Collective intentions and actions. In P. R. Cohen; J. Morgan; and M. E. Pollack (eds.): Intentions in Communication. Cambridge, Mass.: The MIT Press, pp. 401-415.

Searle, John R. (1995). The Construction of Social Reality. New York: Simon \& Schuster. London: Penguin Books, 1996 (Paperback ed.).

Sellen, Abigail; and Richard H. R. Harper (2001). The Myth of the Paperless Office. Cambridge, Mass.: MIT Press.

Svartvik, Jan; and Randolph Quirk (eds.) (1980). A Corpus of English Conversation. Lund, Sweden: C W K Gleerup.

Tanney, Julia (2013). Prolegomena to a cartographical investigation of cause and reason. In G. D'Oro and C. Sandis (eds.): Reasons and Causes: Causalism and Non-Causalism in the Philosophy of Action. London: Palgrave MacMillan, pp. 124-140. - History of Analytic Philosophy Series.

Tenenberg, Josh; Wolff-Michael Roth; and David Socha (2016). From I-awareness to weawareness in CSCW. Computer Supported Cooperative Work (CSCW). Vol. 25, no. 4-5, 2016. - [Special issue: Reconsidering 'Awareness' in CSCW].

Tomasello, Michael; and Hannes Rakoczy (2003). What makes human cognition unique? From individual to shared to collective intentionality. Mind \& Language. Vol. 18, no. 2, April 2003, pp. 121-147.

Tomasello, Michael; Malinda Carpenter; Josep Call; Tanya Behne; and Henrike Moll (2005). Understanding and sharing intentions: The origins of cultural cognition. Behavioral and Brain Sciences. Vol. 28, no. 5, October 2005, pp. 675-735.

Tomasello, Michael (2008). Origins of Human Communication. Cambridge, Mass., and London: The MIT Press.

Tomasello, Michael (2009). Why We Cooperate. Cambridge, Mass., and London: The MIT Press.

Tomasello, Michael (2014). A Natural History of Human Thinking. Cambridge, Mass., and London: Harvard University Press.

Tuomela, Raimo; and Kaarlo Miller (1988). We-intentions. Philosophical Studies. Vol. 53, 1988, pp. 367-389. 
Wittgenstein, Ludwig (1945-49). Philosophical Investigations. (Manuscript). Transl. from Philosophische Untersuchungen. Transl. by G. E. M. Anscombe. Text ed. by G. E. M. Anscombe and R. Rhees. Oxford: Blackwell Publishers, 3rd ed., 2001.

Wittgenstein, Ludwig (1946-47). Wittgenstein's Lectures on Philosophical Psychology, 1946-47. Notes by P. T. Geach, K. J. Shah, A. J. Jackson. Text ed. by P. T. Geach. Chicago: University of Chicago Press, 1988. 